\title{
Juan Goytisolo y Marruecos
}

\author{
Juan Goytisolo and Morocco
}

Bernabé LÓPEZ GARCÍA

Universidad Autónoma de Madrid

bernabe.lopezg@uam.es

Para citar este artículo: Bernabé López García (2017), “Juan Goytisolo y Marruecos" Revista de estudios internacionales mediterráneos, 22, 187-201.

Para acceder a este artículo: https://doi.org/10.15366/reim2017.22.009

No se trata en este trabajo de hacer un inventario de la presencia de Marruecos en la obra de Juan Goytisolo. Es algo, sin duda, hecho mil veces por escritores, periodistas, traductores, fans y amigos del escritor recientemente desaparecido. Desde el censo y clasificación del léxico de origen árabe en su "Don Julián" que trazara el profesor Bernard Loupias en el Bulletin Hispanique", hasta las reflexiones sobre las traducciones al árabe del autor realizadas por un estudioso marroquí de la obra goytisoliana, Ahmed Berremdan², el papel representado por Marruecos en la obra de Juan Goytisolo es más que conocido.

Por otra parte, si el reconocimiento a la aportación a la literatura de Juan Goytisolo no tiene detractores, fuera de algún rencoroso o cegato crítico o lector, el reproche a su supuesto silencio sobre la situación política vivida en Marruecos a lo largo de las cuatro décadas que lo acogieron en su suelo, suele ser frecuente, incluso entre defensores acérrimos de su buen hacer literario.

No trataré en este trabajo de desmontar -o desmentir- dicho reproche sino de aportar elementos desconocidos o poco conocidos que nos permitan situar realmente a Juan Goytisolo en su escenario vital y en su visión y posición sobre el Marruecos que le tocó vivir.

Dejemos a un lado las impresiones que el Tánger del otoño de 1965, cuando por primera vez se acerca a Marruecos, producen en él. Reciente aún la resaca del Tánger internacional y vivos aún los ecos de ese "pasado supuestamente glorioso", su mirada guarda aún algo, así lo reconoce, "de la visión romántica del forastero", pero la combina con una "labor minuciosa de orden empírico",

\footnotetext{
${ }^{1}$ Tomo LXXX, 1978, pp. 229-262.

${ }^{2}$ Ahmed Berremdane, "Reflexiones sobre los textos de Juan Goytisolo, traducidos en la prensa árabe y marroquí en particular", en F. de Ágreda, La traducción y la crítica literaria: actas de las Jornadas de Hispanismo árabe, 1990, pp. 235-238.
} 
de verdadero "agrimensor" ${ }^{3}$, para describir lo que ve. Será allí, desde las terrazas del café Hafa o el mirador del Bulevar Pasteur donde fragüe las "sombrías traiciones" de su Reivindicación del Conde Don Julián ${ }^{4}$.

Nos importa en este trabajo no la mirada literaria sobre la realidad marroquí que lleva a la creación de obras como la citada o Makbara ${ }^{5}$, sino sus juicios sobre el país, su régimen, sus políticos, su oposición, su relación en suma con el país, junto a las vivencias con sus conciudadanos en su vida cotidiana.

\section{Goytisolo, Marruecos y el Sahara}

Su simpatía y proximidad con el norte de África se había manifestado ya en los años de la guerra de Argelia expresando su solidaridad con el movimiento de liberación y viajando, en julio de 1963, en compañía de Jean Daniel y Gisèle Halimi, al país recién liberado. No he sabido encontrar sin embargo escritos de Juan Goytisolo sobre Marruecos antes de mayo de 1976 en que publicara en la revista Triunfo su polémico artículo "La izquierda española, los nacionalismos magrebís y el problema del Sáhara" ${ }^{6}$. Artículo que es, ante todo, una requisitoria contra la larga trayectoria de los partidos de la izquierda española, PSOE y PCE, ante una colonización como la española en el norte de Marruecos que fue vista mayoritariamente con anteojeras españolistas eludiendo o ignorando una solidaridad directa con las víctimas de dicha colonización, los marroquíes.

Debo recordar que detrás de la actitud expresada en dicho artículo por Goytisolo está el impacto causado en él por un libro que inauguró sin duda el revisionismo sobre la colonización de Marruecos, olvidada ya dos décadas atrás y recordada sólo por nostálgicos del militarismo africanista. Me refiero a El colonialismo español en Marruecos ${ }^{7}$ de Miguel Martín, seudónimo del entonces militante comunista y futuro periodista Fernando López Agudín. Es posible que este libro no resista hoy, desde un punto de vista historiográfico, una segunda lectura, escrito a vuela pluma desde las tripas de un melillense izquierdista saturado de franquismo desde la infancia. Pero sin duda marcó a una generación de lectores, de estudiosos, arabistas o historiadores, en busca de un relato coherente sobre la relación de España y Marruecos, impregnado de una profunda mala conciencia por la ocasión perdida, imaginada, del desentendimiento entre dos pueblos, el marroquí y el español, ambos oprimidos, que favorecieron, con su separación, a la opresión.

El libro de Martín causó, paralelamente, un gran impacto, que serviría más tarde de justificación, también de coartada, a amplios sectores del nacionalismo marroquí, tanto de izquierda como de derecha. Desde Mohamed Larbi Messari, del partido del Istiqlal, hispanista, en sus artículos en L'Opinion y Al-Alam, a Ali Yata, del PPS excomunista, que conoció el libro a través de los extractos traducidos por Simon Lévy y publicados en Al-Bayane, las referencias a este libro para fustigar a la izquierda española en su tratamiento torcido del problema marroquí en el pasado, fueron continuas en Marruecos en los años en que la cuestión sahariana estuvo en el proscenio de la vida

\footnotetext{
${ }^{3}$ En el documental "Esta es mi tierra-Paisaje después de la batalla, por Juan Goytisolo", de RTVE, refiriéndose al trabajo realizado por el propio autor en la etapa previa a la redacción de su novela "Don Julián".

4 Joaquín Mortiz, México, 1970; Seix Barral, Biblioteca Breve, Barcelona 1976. Reedición revisada en 2001, Don Julián, en Galaxia-Gutenberg, Barcelona.

${ }^{5}$ Seix Barral, Barcelona 1980.

${ }^{6}$ Triunfo, 8 y 15 de mayo de 1976. Este artículo formaría parte del libro de Goytisolo El problema del Sáhara, Anagrama, Colección Ibérica, Barcelona 1979, pp. 17-66.

${ }^{7}$ Ruedo Ibérico, París 1973.

188
} 
política ${ }^{8}$. Juan Goytisolo se unirá a estos reproches con su artículo citado, afirmando "la existencia y legitimidad de las reivindicaciones nacionales del pueblo de Marruecos".

Con una vehemencia como la de "Julián Goytisolo Boabdil el chico" ${ }^{9}$ en su Don Julián contra la España Sagrada, arremeterá en su extenso artículo sobre el Sahara contra lo que considera una verdad prefabricada, que circulaba como "moneda contante y sonante" en la España "semiindependizada" de 1976, fruto de un "maniqueísmo político elemental" alimentado durante 40 años de pensamiento acrítico.

El artículo debe ser entendido en su contexto de 1976, en que se había instalado del lado español un unanimismo solidario hacia el movimiento saharaui tras una connivencia clara entre dos dictaduras, la franquista y la hassaniana, unanimismo que impedía ver el punto de vista marroquí, con una larga historia de reivindicaciones nacionales, de derecha e izquierda, negadas insistentemente por el régimen español que hizo todo lo posible por desconectar las elites marroquí y saharaui, creando en la colonia un sentimiento hostil hacia Marruecos desde la conversión en provincia del territorio del Sahara Occidental en 1958.

Es posible que la apuesta por la izquierda marroquí que Goytisolo hace en su artículo pecase en aquel momento de la misma ingenuidad en que aquella cayó al creer que la coyuntura de la "recuperación" (según la perspectiva marroquí) del Sahara abría un tiempo nuevo a Marruecos con esperanzas de libertad. Goytisolo escribirá:

"La utilización de las potencialidades creadas por el problema del Sáhara con vistas a canalizar la movilización popular hacia una apertura política y democrática, la justicia social y un programa de control popular sobre los actos y opciones del Gobierno, es un asunto que las fuerzas marxistas de Marruecos deben decidir por su cuenta, sin necesidad de consejos ni amonestaciones de nadie ${ }^{10}$.

Que finalmente fuera Hassan II quien controlara todo el proceso, traicionando en las elecciones de 1977 las promesas democratizadoras, es algo muy fácil de ver a posteriori pero no lo era en el momento de escribir el artículo. Baste leer el libro de Abdallah Laroui Marruecos y Hassan II. Un testimonio $^{11}$ para corroborarlo. La respuesta que el artículo de Goytisolo motivó en la misma revista Triunfo por un profesor de relaciones internacionales socialista, Emilio Menéndez del Valle, intenta achacar a Goytisolo unas anteojeras producidas por su "bellísima y aséptica atalaya tangerina, al otro lado del Estrecho, mientras añora a don Julián"12. Una forma de descalificar lo que tuve la oportunidad de comprobar viviendo, como Goytisolo, del otro lado del Estrecho acontecimientos como la Marcha Verde, percibidos bajo su ángulo antifranquista y anticolonial.

\footnotetext{
${ }^{8}$ Hasta 1988 no apareció en Rabat la traducción al árabe de esta obra realizada por Abd al-Aziz al-Udiyi en Ediciones Manchurat al-Tell.

${ }^{9}$ Retomo aquí la expresión de Manuel Vázquez Montalbán en su artículo "Juan Goytisolo o la reivindicación de Boabdil el chico", en Triunfo, 451, 23 de enero de 1971, pp. 62-64.

${ }^{10}$ El problema del Sáhara, p. 30-31.

${ }^{11}$ Siglo XXI, Madrid 2007.

12 Ibid., p. 122.
} 
Que la realidad era más compleja, no hay duda. Que Goytisolo no se equivocaba desmontando el mito del progresismo del régimen de Bumedian en unos tiempos en que se adulaba a Santiago Carrillo o a Felipe González recibiéndolos con honores de jefes de Estado a su paso por Argel, el tiempo le ha dado la razón. Pero sí se equivocaba en su apuesta por una "actuación enérgica y eficaz de los partidos progresistas" marroquíes para evitar que la reintegración del territorio saharaui al "conjunto mauritano-marroquí del que siempre formó parte" fuese en beneficio exclusivo de las "fuerzas oligárquicas y feudales". No hay más que ver, cuarenta años más tarde, la opulencia de la oligarquía y el trono en Marruecos, la situación de precariedad de sectores importantes del pueblo marroquí, el desgarro en la vida de los saharauis, separados aún entre Tinduf y el territorio del Sahara Occidental, y también, y sobre todo, la práctica desaparición de los partidos progresistas.

Dos años más tarde Goytisolo vuelve sobre el tema en el diario El País con su artículo "El Sáhara, dos años después" ${ }^{13}$. El problema sahariano había degenerado entre tanto en guerra abierta entre el ejército marroquí y el Frente Polisario, apoyado logísticamente por Argelia. Goytisolo tratará de hacer de abogado del diablo para desmontar los prejuicios antimarroquíes que continuaban larvados en las declaraciones de políticos españoles de todo signo, denunciar la desinformación general sobre las realidades magrebíes en España, desinflar las estadísticas agigantadas a propósito de los habitantes del Sahara, llamar la atención sobre la naturaleza de los acampados en Tinduf, señalar las dos acepciones que el principio de libre autodeterminación puede tener según la lógica argelina de intangibilidad de fronteras o la marroquí de reconstitución de un estado histórico, para terminar evocando la crisis hispano-argelina a propósito del MPAIAC y las Canarias. Defendiéndose de la acusación de promarroquí concluirá que:

"El prejuicio promarroquí de que me acusan quienes apoyan ciegamente las tesis de una independencia prefabricada y selectiva es en realidad un prejuicio promagrebí o, para ser más exactos, proárabe: mis simpatías van por igual a los pueblos -y no, desde luego, a los Gobiernos- de Marruecos y Argelia, así como a las poblaciones saharauis que he tenido ocasión de conocer y apreciar durante mis nomadeos por la zona anteriores al conflicto"14.

Su serie de artículos en El País tuvo una respuesta en la contra-serie de Pedro Costa Morata, "Reivindicación de la causa saharaui" ${ }^{15}$. La escasa argumentación de este autor y la carga de vehemencia contra Goytisolo que destilan los cuatro artículos que la compusieron no pasan de ser descalificaciones. En su respuesta, Goytisolo señalará que su

"tentativa de trasladar la compleja problemática del Sahara desde el campo de los actos y manifestaciones de estricta militancia al de los análisis y razonamiento ha topado con el emocionalismo de quien, en vez de fundar su militancia en la lucidez, sacrifica enteramente ésta a sus anhelos confusos de militancia"16.

El gran reproche a Goytisolo vuelve a ser, una vez más, su "atalaya tangerina". Costa Morata acusará:

\footnotetext{
${ }^{13}$ Aparecido el 17, 18, 20, 23, 24, 25 y 26 de mayo de 1978. Sería incluido en el libro citado El problema del Sáhara.

${ }^{14}$ El problema del Sáhara, p. 104.

${ }^{15}$ El País, 29 de agosto de 1978. Le siguieron “El gran Marruecos, un sueño nacional-fascista” el 30 de agosto, "La fobia anti-argelina”, el 31 de agosto y "Las izquierdas paralelas", el 1 de septiembre de 1978. Estos artículos no fueron incluidos en el libro El problema del Sáhara (como sí lo fue el de Menéndez del Valle), pero sí la "Respuesta a Costa Morata con el Sáhara al fondo", publicada en El País del 5 al 8 de octubre de 1978.

${ }^{16}$ El problema del Sáhara, p. 151-152. 
"He visto con desolación (¿humanitarismo selectivo o cuantitativo?) que no firma manifiestos contra la represión -feroz, por cierto- en Marruecos. Seamos claros: esta postura anti-represión liquidaría la entusiasta experiencia marroquí del escritor"17.

Es cierto que la represión en Marruecos contra el grupo marxista-leninista Ila Al-Amam estaba, en el momento de escribirse estos artículos, en pleno apogeo. Las duras condenas a Abraham Serfaty y sus compañeros por no abrazar las tesis oficiales marroquíes sobre el Sahara y reclamar la autodeterminación de los saharauis fueron silenciadas en Marruecos por una oposición que juzgó a los militantes bajo el signo de la traición. Craso error pues la represión, como se vería más tarde, no se detendría ahí.

Y es cierto el silencio de Goytisolo a este respecto. Un silencio que, debemos reconocer, también mantuvimos algunos por desconocimiento. Si firmó o no algún manifiesto en Francia no estoy en disposición de afirmarlo.

\section{El manifiesto de intelectuales españoles y marroquíes de 1979}

Sí, en cambio, hay que recordar que en mayo de 1979 sería uno de los principales recogedores de firmas para un "Manifiesto de intelectuales españoles y marroquíes" que, inspirado por el hispanista marroquí Mohamed Larbi Messari, redacté, con retoques del corresponsal de la Agencia MAP en Madrid, Mohamed Chakor, y que El País publicó como publicidad con la financiación, imagino, de la Embajada marroquí en Madrid. Embajada que tuvo la ocurrencia de publicarlo también en el periódico El Alcázar, el más reaccionario de los que se publicaban por entonces en España. Desde luego que no tuve la más mínima intervención en esta contradictoria ocurrencia publicística que deslegitimaba, de entrada, una operación que pretendía acercar las opiniones públicas española y marroquí.

\footnotetext{
17 “La fobia anti-argelina”, El País, 31 de agosto de 1978.
} 


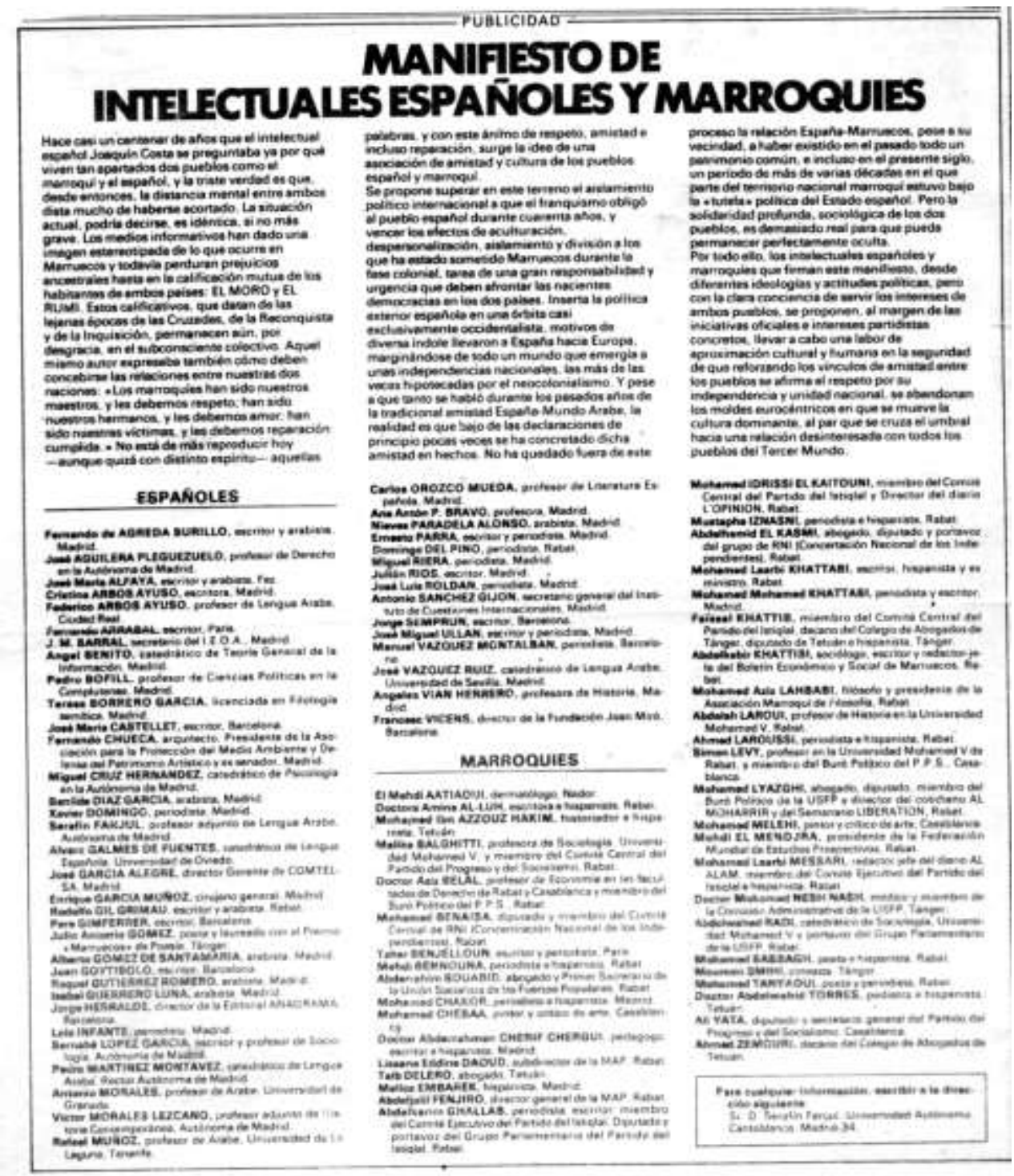

Es posible que pocos hayan conocido el disparate de la aparición del manifiesto en este órgano golpista, pero creo de honestidad hacerlo público, para revelar las incongruencias de la política marroquí hacia España, o mejor, los extraños apoyos en que se sustentaba el inexistente lobby hispano-marroquí en nuestro país en aquellos años ${ }^{18}$.

El manifiesto pretendía combatir los prejuicios ancestrales en nuestras respectivas opiniones públicas, apelaba al espíritu de Joaquín Costa de respeto, amistad y reparación hacia los marroquíes, y proponía una aproximación cultural y humana a través de una asociación de amistad y cultura de los pueblos español y marroquí. La idea, loable, fue apoyada por 48 firmantes españoles y 40 marroquíes. Pero lo singular era el desequilibrio intelectual y político entre los firmantes de uno y otro lado del Estrecho.

Del lado marroquí se encontraba la flor y nata de la clase política, con los líderes de los principales partidos Abderrahim Buabid de la USFP, Alí Yata del PPS, dirigentes de estos dos partidos progresistas como Mohamed Lyazgui, Abdelwahed Radi, Aziz Bellal, Simon Lévy, Malika Balghitti, varios miembros influyentes del partido del Istiqlal como Abdelkrim Ghallab, Mohamed Idrissi Kaituni, el citado Mohamed Larbi Messari, el portavoz del partido gubernamental Reagrupamiento

\footnotetext{
${ }^{18}$ Hice referencia a ello en el artículo "La sociedad civil y las relaciones con Marruecos: el comité Averroes, ¿un instrumento para el acercamiento entre las sociedades o la retórica de la mediación civil?”, en Miguel Hernando de Larramendi y Aurelia Mañé Estrada (Eds.), La política exterior española hacia el Magreb. Actores e intereses, Ariel Ciencia Política-Real Instituto Elcano, Madrid 2009, pp. 195-209.
} 
Nacional de los Independientes (RNI), Abdelhamid El Kasmi y un destacado miembro del mismo, Mohamed Benaissa, así como un nutrido grupo de intelectuales y artistas como Tahar Benjellun, Mohamed Chebaa, Mohamed Aziz Lahbabi, Abdallah Larui, Mohamed Melehi, Mehdi El Menjra, Abdelkebir Khatibi y conocidos hispanistas como Mohamed Ibn Azzuz Hakim, Malika Embarek, Mustapha Isnazni y el citado Mohamed Chakor, entre otros.

Del lado español el panorama era otro. Ni un solo representante de la clase política, ni de izquierda ni de derecha. $Y$ tres grupos de firmantes: el de los arabistas, recogidos por Serafín Fanjul $^{19}$ y yo mismo, el de los amigos de Juan Goytisolo y los periodistas ligados a Marruecos o en el entorno español de Mohamed Chakor.

Entre los arabistas, en el momento de la firma tan sólo era una personalidad conocida Pedro Martínez Montávez, rector de la Universidad Autónoma de Madrid. Los demás eran, salvo el caso de los catedráticos Miguel Cruz Hernández, Álvaro Galmés y José Vázquez, profesores no numerarios como el citado Fanjul, Federico Arbós, Rafael Muñoz, Antonio Morales, José Aguilera o yo mismo, directores de centros culturales en Marruecos como Rodolfo Gil, Fernando de Ágreda y José María Alfaya o alumnos de las dos primeras promociones de egresados del departamento de Estudios Árabes e Islámicos de la UAM (Alberto Gómez, Benilde García, Raquel Gutiérrez, Isabel Guerrero, Nieves Paradela). En la órbita de los arabistas se encontraba el historiador Víctor Morales Lezcano.

Juan Goytisolo debió movilizarse para recoger firmas tan sorprendentes como las de Jorge Semprún, Manuel Vázquez Montalbán, Fernando Arrabal, Xavier Domingo, José María Castellet, José Miguel Ullán, Julián Ríos, Jorge Herralde, Pere Gimferrer y Francesc Vicens, director de la Fundación Joan Miró que acogería en Barcelona un año más tarde una reunión de este grupo de intelectuales hispano-marroquíes que no llegaría a tener continuidad ${ }^{20}$.

Un tercer grupo se componía de periodistas especializados en mundo árabe y Magreb como Domingo del Pino, corresponsal en Rabat de El País, Lola Infante, arabista y periodista en Diario 16, José Luis Roldán y Antonio Sánchez Gijón. No sabría situar en estos tres grupos a otros firmantes entre los que se encontraba el arquitecto y exsenador Fernando Chueca.

Goytisolo aparecía como muñidor de estos encuentros intelectuales pero en los que nunca, ni Semprún, Vázquez Montalbán, Gimferrer, Castellet o Arrabal aparecieron.

\footnotetext{
${ }^{19}$ Que figura al pie del manifiesto como correo "para cualquier información" en la dirección de la Universidad Autónoma de Madrid (UAM).

${ }^{20}$ Un año antes, en diciembre de 1979, tuvo lugar en Marrakech lo que se llamó el Segundo Encuentro de intelectuales hispano-marroquíes. Goytisolo participó y publicó por entonces en El País (20 de diciembre de 1979) un artículo sobre el desencuentro en las relaciones hispano-marroquíes titulado “¿Condenados a entenderse?”. El primero de estos encuentros, más minoritario, había tenido lugar en Madrid en mayo de ese año con motivo de la publicación del manifiesto. Ver referencia en "Encuentro de intelectuales españoles y marroquíes", sin firma, en EI País de 31 de mayo de 1979.
} 


\section{Los sucesos de Casablanca de 1981}

Desmintiendo la acusación de Costa Morata de que Goytisolo no firmaba manifiestos contra la represión en Marruecos para no hacer peligrar su "entusiasta experiencia marroqui", debo decir que tras la dura represión ejercida por los sucesos de Casablanca durante la huelga general de junio de 1981, Goytisolo ejerció una vez más de firmante y recolector de firmas para una carta al director de El País en la que, como "intelectuales amigos de Marruecos" e identificándose como firmantes del manifiesto de 1978, consideraban que "los acontecimientos de Casablanca (...) suponen un duro golpe a la imagen que Marruecos se esforzaba en dar en los últimos años" y reclamaban la reaparición de la prensa izquierdista suspendida (Al-Muharrir y Al-Bayane), el esclarecimiento de las responsabilidades de los sucesos considerando "insatisfactoria la versión oficial de los mismos", así como la plena libertad de información, asociación y de huelga. De nuevo, entre los firmantes, los arabistas y los goytisolianos: Federico Arbós, José María Castellet, Serafín Fanjul, Pere Gimferrer, Juan Goytisolo, Lola Infante, Fernando López Agudín, Bernabé López García, Juan Madrid, Pedro Martínez Montávez, Elisa Molina, Víctor Morales, José Miguel Ullán y Francesc Vicens, por entonces diputado del Parlament de Cataluña ${ }^{21}$.

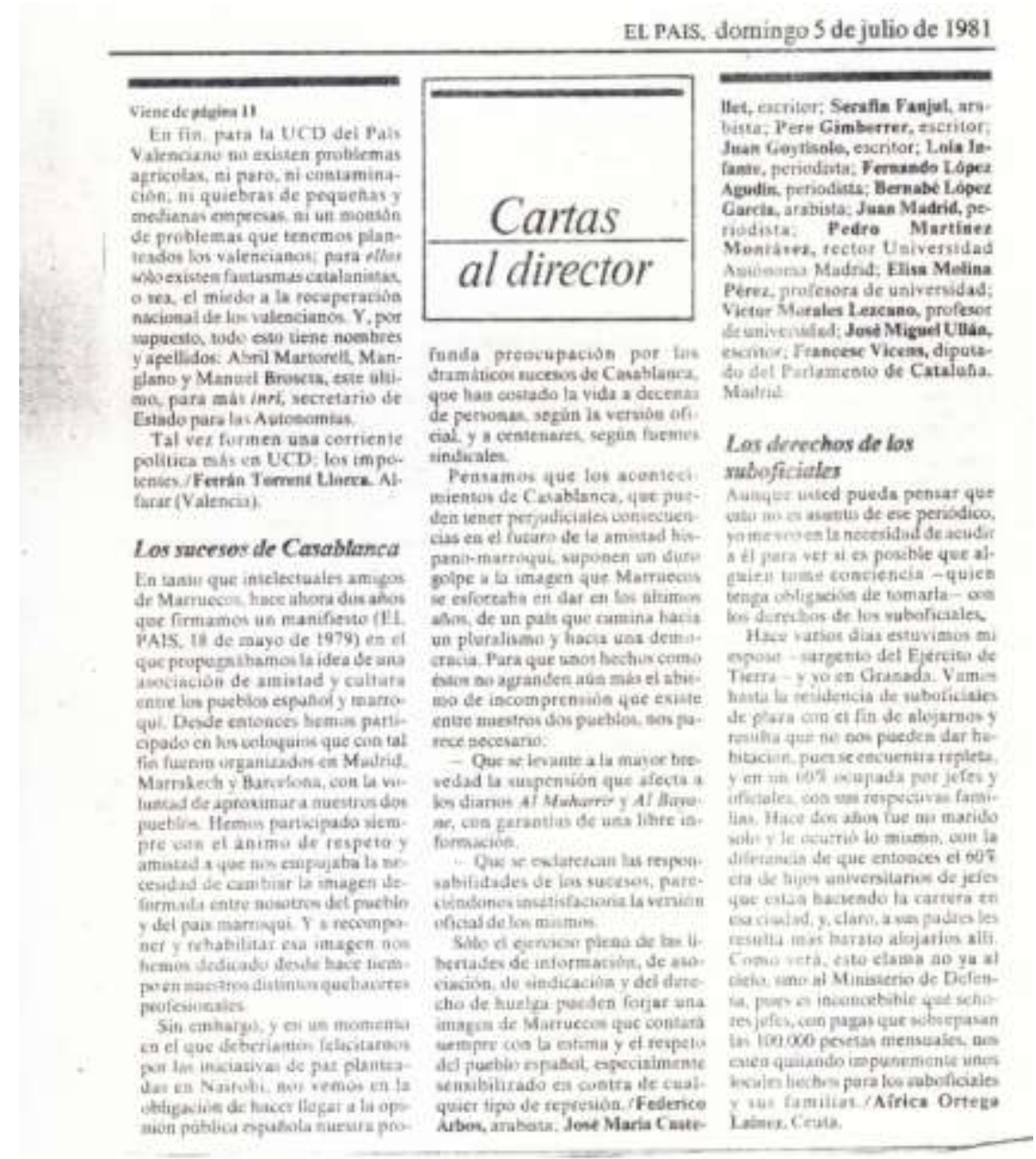

\footnotetext{
${ }^{21}$ La carta fue "urdida" por Lola Infante y yo mismo, que nos encargamos de entregarla en mano al embajador de Marruecos, Maâti Jorio. 


\section{Marroquíes en España}

Llegó la hora de la inmigración marroquí a España y Juan Goytisolo la adoptó como un tema recurrente en sus artículos de opinión denunciando actitudes de incomprensión y racismo en sectores de nuestra sociedad. Muchos de esos artículos fueron recogidos en el libro España y sus Egidos $^{22}$, entre ellos uno de los más antiguos, publicado en El País, "Morir con los zapatos puestos" ${ }^{23}$, donde narró con amarga ironía el destino fatal del emigrante-transeúnte Abdellah Arrouch, muerto por la policía en la estación de Chamartín. Aunque por entonces escenas de la explotación de los inmigrantes marroquíes se venían dando en Cataluña, última frontera "libre" de visados para el acceso a una Europa que empezaba a cerrarse como fortaleza, no fue hasta la ley de Extranjería de 1985 y el proceso de regularización que comportó que la inmigración marroquí empezó a ser sentida en la España de entonces. Con las incongruencias que resultaban de considerar como inmigrantes a "los musulmanes nacidos o asentados desde hace largo tiempo en Ceuta y Melilla”. A ello dedicó Goytisolo su artículo "De la OTAN a la ley de extranjería”"24.

La inmigración "inesperada" de que nos habló Antonio Izquierdo ${ }^{25}$ llegó y creció, buscando su acomodo en nuestro país con años de retraso con respecto a otros países de Europa. En el Taller de Estudios Internacionales Mediterráneos (TEIM) de la Universidad Autónoma, iniciamos una investigación en profundidad sobre el tema migratorio magrebí, plasmada en un Atlas de la inmigración magrebí en España ${ }^{26}$ (1996) al que quisimos asociar a muchos de los especialistas que sobre la emigración o la historia de las relaciones hispano-magrebíes contaban por entonces en España. Juan Goytisolo se brindó a prologarlo y parece oportuno rescatar dicho "Prefacio" en este artículo.

\section{“PREFACIO}

Nos encontramos ante un libro esencial. La controversia originada entre quienes se alarman por la supuesta invasión de la Península por los inmigrantes magrebíes -resucitando con ello los fantasmas y estereotipos del moro desde la Reconquista hasta la guerra civil- y los que, animados de sentimientos antirracistas y solidarios, defienden el status de los inmigrados y su inserción en nuestra sociedad no se funda a menudo en un conocimiento cabal de los hechos: de sus causas e historia, de los problemas sociales y legales a los que se enfrentan los recién llegados así como los que crean su exclusión y rechazo por diversos sectores de la población. El conjunto de ensayos que integran el Atlas de la inmigración magrebí en España abarca el tema en su compleja diversidad de componentes y matices.

\footnotetext{
${ }^{22}$ Hijos de Muley Rubio, Majadahonda (Madrid) 2003.

${ }^{23}$ El País, 26 de octubre de 1984.

${ }^{24}$ El País, 6 de marzo de 1986. Goytisolo sería cofirmante con Antonio Gala y Manuel Vázquez Montalbán de un escrito titulado "Por la distensión en Melilla y Ceuta", publicado en El País, el 13 de febrero de 1987 y que suscribían, una vez más, personas del entorno arabista y goytisoliano, así como algunos exrectores como Francisco Bustelo o Julio González Campos y profesores como Antonio Elorza, Alejandro Lorca o Roberto Mesa. Para más indicaciones, el redactor del artículo y muñidor de las firmas fue el que esto suscribe.

${ }^{25}$ A. Izquierdo, La inmigración inesperada. La población extranjera en España (1991-1995), Trotta, Madrid 1996.

${ }^{26}$ Dirigido por mí mismo y coordinado por Ana I. Planet y Ángeles Ramírez, fue publicado por la UAM y el Observatorio Permanente de la Inmigración. Reunió 70 colaboradores y especialistas.
} 
Tras su lectura, resulta posible tratar del asunto con mayor conocimiento de causa y menor pasión y apriorismo.

La iniquidad de las relaciones entre Norte y Sur constituye desde luego el factor primordial. La explotación del segundo por el primero y el muy diferente porcentaje de crecimiento demográfico entre ambos bastarían para explicar el fenómeno: si la riqueza -inversiones en el sector agroalimentario, ayuda económica, etcétera- no va a los países pobres, serán los pobres quienes acudirán a ella. Pero esta explicación debe completarse y graduarse a la luz de la geografía y la historia: España es la frontera sur del Norte, el Magreb la frontera norte del Sur. El papel de Marca Hispánica que la comunidad Europea nos asigna no debe enquistarnos en una mentalidad cerril y estéril de meros guardianes de la supuesta fortaleza asediada: las fronteras han sido siempre porosas y las corrientes migratorias de una a otra orilla del Mediterráneo han sido, son y serán la regla, no la excepción. La civilización mediterránea no existiría sin un trasvase incesante de poblaciones, costumbres, ideas, culturas. No hay un solo país de su cuenca que no haya sido fecundado por el contacto, comercio o rivalidad con los pueblos de la otra orilla. El objetivo de Roma convertir al Mediterráneo en lago- no puede repetirse: ni la invasión árabe, ni las Cruzadas, ni el poder otomano lograron unificar lo que es abigarrado, divergente y múltiple. Entre 1800 y 1962, Francia e Inglaterra, secundadas por Italia y España, prolongaron el espíritu de conquista de la Cristiandad. La última guerra intestina entre potencias europeas (193945) acabó con su sueño imperial. Hoy el Mediterráneo vuelve a ser lo que fue aunque la correlación de fuerzas entre Norte y Sur desnivele brutalmente los platillos de la balanza en favor de las antiguas metrópolis.

Pero la terca realidad permanece: durante siglo y medio, España, Francia e Italia enviaron a centenares de millares de emigrantes a colonizar el Magreb a la sombra de sus ejércitos; hoy, nuestros antiguos protegidos o colonizados vienen a buscarse pacíficamente los garbanzos en nuestro suelo como secuela de dicha colonización. Esta corriente inversa severamente controlada por un arsenal de leyes y medidas represivas- responde sin duda a una exigencia objetiva: como en el resto de los países comunitarios con excepción de Grecia e Irlanda, los inmigrantes vienen a cumplir los trabajos más penosos y duros, que ningún español, "nuevo europeo» está dispuesto a realizar. Si su utilidad social y económica es así palmaria, las disposiciones legales vigentes no tienen en cuenta dicha necesidad. Las condiciones de acogida siguen siendo insuficientes y precarias, el clima de hostilidad de una buena o, por mejor decir, mala parte de la población española -el $26 \%$ de los jóvenes desearían la expulsión de los moros según una reciente encuesta del diario EL PAÍSconducen a actitudes xenófobas y a un aumento inquietante de las agresiones y asesinatos racistas"

El Atlas de la inmigración magrebí en España desdramatiza eficazmente el sentimiento de inseguridad suscitado por las nuevas corrientes migratorias. Analiza región por región los problemas planteados por las mismas y sus posibles soluciones. Demuestra la índole retrógrada de la actual Ley de Extranjería. Denuncia la explotación de los negreros sin escrúpulos y los abusos y arbitrariedades de la policía.

¿Que sería en efecto de la agricultura del Maresme en Cataluña y de los tempranales de EI Ejido en Almería sin la sufrida y silenciosa labor de la mano de obra magrebí y africana? Bastaría con formular la pregunta para probar la falsedad y mala fe de la equiparación inmigración-paro. Los inmigrantes magrebies no quitan el sueldo a nadie. Como sus antepasados moriscos, son creadores de riqueza y por ello mismo tienen derecho a formar parte de nuestra sociedad. 
Digámoslo bien claro: estos musulmanes que se expresan en nuestra lengua no constituyen un fenómeno temporal ni su presencia obedece a una mera coyuntura económica. Como en otros países comunitarios, han venido a integrarse en nuestra sociedad con su cultura y costumbres. España no puede escapar a esta regla europea que se inscribe además en su historia: nuestras ciudades son y serán cada vez más mestizas. Lo que fue pasado empieza a ser ya presente y prefigura nuestro porvenir. Los nuevos moriscos no han desembarcado con armas ni espíritu de venganza: lo hacen en busca de una vida decente y embebidos a veces de un sentimiento de nostalgia. Recuerdo las bellas palabras de una marroquí detenida en Almería cuando su patera fue interceptada por la guardia civil durante el verano pasado: "yo sólo había venido a compartir con los españoles el sabor de las naranjas que plantaron aquí mis antepasados».

\section{Juan Goytisolo}

\section{Patrimonio oral de la humanidad}

Estamos en 1996. En marzo, Goytisolo publica en El País su artículo "Patrimonio oral de la humanidad" 27 en el que canta la resistencia "a los embates conjugados del tiempo y una modernidad degradada y obtusa" de Xemaá-El-Fná, la mítica plaza pública de Marrakech, ciudad única que "mantiene hoy el privilegio de abrigar el extinto patrimonio oral de la humanidad, tildado por muchos de 'tercermundista'". Nacerá de ahí la idea, más tarde consagrada por la UNESCO en junio de 1997, de reconocer dicha plaza como Patrimonio oral de la humanidad.

Por esas fechas también fue creado el Comité Averroes que pretendía reunir "un grupo activo de conocedores y expertos de las sociedades respectivas [española y marroquí] que pudieran aportar con su reflexión ideas para evitar las crisis cíclicas" ${ }^{28}$ que afectaban a las relaciones hispanomarroquíes. No sé si en la propuesta inicial de miembros que el ministro Carlos Westendorp pasó a su sucesor Abel Matutes estuvo o no Juan Goytisolo y fuera o no vetado ${ }^{29}$ por sus posicionamientos en temas como Ceuta y Melilla. Las tensiones entre PP y PSOE en aquel primer traspaso de poderes estaban en un momento álgido y José María Aznar siempre temió que dicho comité pudiera encubrir la famosa célula de reflexión sobre las ciudades norteafricanas tan querida a Hassan II. La cuestión es que Goytisolo no figuró entre los miembros de aquel primer comité.

Cuando muerto Hassan II y retornado el gobierno a manos del PSOE, el nuevo ministro de Exteriores, Miguel Ángel Moratinos, intentó resucitar en 2005 un comité que había languidecido sobre todo a raíz del enfriamiento de relaciones entre España y Marruecos tras la retirada del embajador en Madrid en octubre de 2001. En esta segunda entrega Goytisolo sí figuró en la parte española, junto a Miguel Ángel Aguilar, Rosa Aguilar, Fernando de Almansa, Raimundo Bassols,

\footnotetext{
${ }^{27}$ El País, 26 de marzo de 1996. En junio de 1997 Galaxia Gutemberg-Círculo de lectores publicó este artículo en cinco lenguas (español, árabe, francés, inglés y alemán) con dibujos de Hans Werner Geerdts procedentes de la obra publicada por la misma editorial en 1995 Lectura del espacio en Xemaá El-Fná.

${ }^{28}$ Véase sobre el tema mi artículo citado en nota 18.

${ }^{29}$ Como fue mi caso y narro en el artículo citado en nota 18.
} 
Ramón Enciso, Federico Mayor, Aldo Olcese, Marcelino Oreja, Jerónimo Páez, José Miguel Zaldo y yo mismo ${ }^{30}$. El balance de esta segunda etapa del comité no fue nada brillante, limitándose a ir a remolque de unas relaciones siempre inestables sin abordar a fondo las dificultades de comunicación entre nuestras respectivas opiniones públicas.

Juan Goytisolo no tuvo una participación activa, estando ausente ya desde la reunión constitutiva de enero de 2005 en Tánger y participando sólo en la realizada en Marrakech el 29 de junio de 2006. En las notas que tomé de su intervención señalé que hizo hincapié en las siempre difíciles relaciones con la administración de cultura en Marruecos. Recordó que cuando en 1975 escribió en París un artículo a favor de las tesis marroquíes, buscó a través de L'Expréss contacto con la embajada de Marruecos con el objeto de difundir su artículo. Nunca encontraría apoyo, fue su conclusión. Lo mismo le ocurrió al plantear su propuesta de lograr el apoyo de la UNESCO para la plaza de Xemaá El-Fná. Por parte marroquí sólo mostraron interés en proyectos "demenciales e infumables" relacionados con la plaza que hubieran desnaturalizado su idea. Su queja a Marruecos fue siempre la desatención a su permanente reclamo de "iAyúdenme a ayudarles!". En la reunión de Marrakech se discutió acerca de un proyectado -y que nunca se realizaría- "Año de Marruecos en España". Goytisolo sugirió que la mejor manera de acercar pueblos podría ser a través de la música, para lo que propuso hacer intervenir los grupos musicales marroquíes asentados en España.

\section{A vuelo de pájaro}

Es cierto que la visión de Marruecos, país de sus vivencias cotidianas, está menos presente que la de otros países de su entorno como Argelia, a la que dedicó la larga serie de artículos "Argelia en el vendaval" ${ }^{31}$ o el mismo Túnez de Ben Alí, al que dedicó un duro artículo, "El Magreb a vuelo de pájaro" ${ }^{32}$, en el que denunciaba "la omnipotencia de la máquina policial del régimen". Es ahí donde ha radicado el reproche de los que, fuera de Marruecos, pero también dentro, hubieran querido un Goytisolo más explícito con las víctimas no sólo de la represión de Ufkir y Basri, "que afloran hoy a la lumbre del agua en el nuevo Marruecos"33, dirá en 2000, sino las que desde entonces siguieron apareciendo en ese "nuevo" Marruecos de Mohamed VI.

Pero con Marruecos, la "militancia" de Goytisolo es de otro tipo. Del que revelan sus llamadas de atención a los gobiernos de Marruecos y España que "deberían escoger el camino de la sensatez y los intereses comunes" en crisis como la de Perejil ${ }^{34}$, demostrando tozudamente estar "condenados al parecer a no entenderse". Ciertamente sus invectivas suelen caer del lado hispano, donde se es tan proclive a ver el contencioso hispano-marroquí por el lado del orgullo nacional "contra el más elemental sentido común y una visión a largo plazo de los intereses económicos, políticos y culturales de España en la orilla sur del Estrecho" ${ }^{35}$.

Pero eso no quita que haya alzado su voz en algunas ocasiones contra periodistas represaliados en el Marruecos de Mohamed VI. Reproduzco aquí un fax que me envió el 20 de febrero de 2003 para ser reproducido como carta al director en El País, en solidaridad con dos directores de periódicos

\footnotetext{
${ }^{30}$ Los miembros marroquíes son citados en el artículo ya mencionado.

${ }^{31}$ Publicada en El País entre el 27 de marzo y el 3 de abril de 1994, en plena guerra civil argelina.

${ }^{32}$ El País, 18 de enero de 2000.

${ }^{33}$ Dirá en el artículo sobre Túnez citado en la nota anterior.

${ }^{34}$ Ver su artículo "Moros en la costa”, en El País, 21 de julio de 2002.

35 Ibid.

198
} 
perseguidos en Marruecos, Abubakr Jamai y Driss Ksikes, directores de Le Journal hebdomadaire y Nichan.

"La modernización de Marruecos, que tanto recuerda a la España de los años sesenta con sus dos millones y pico de emigrantes a la Europa comunitaria y otro tanto de turistas ansiosos de sol barato, enfrenta al país a una serie de retos: reducir el margen que separa el mundo rural del urbano y, dentro de éste, a quienes poseen mucho y quienes no poseen nada. Para ello resulta indispensable profundizar el actual proceso democratizador y, por consiguiente, defender el papel que debe desempeñar en él una prensa libre e independiente.

Uno de los logros de los últimos tiempos, junto a los buenos datos macroeconómicos y una mayor apertura informativa, ha sido el de crear una opinión pública consciente de la necesidad de la crítica y la autocrítica tanto en el campo político como en el social y cultural. Dicha dinámica de adaptación a la normativa universal de la libertad de prensa choca no obstante con las trabas impuestas a una prensa joven, reflejo de las aspiraciones de un gran sector de la población a un Marruecos más justo y democrático.

Los artículos publicados en El País por dos directores de semanarios represaliados como Aboubakr Jamaï y Driss Ksikes han llenado de inquietud a quienes sostenemos desde hace años una política de buen entendimiento con Marruecos como la de nuestro actual Gobierno. Ningún país puede avanzar sin el concurso de voces diversas y críticas. Condenar al silencio a dos periodistas independientes es invitar a la autocensura a sus compañeros de pluma, contrariamente a los intereses y la credibilidad de un país vecino y amigo, cuyo progreso, modernización e integridad defendemos".

Juan 


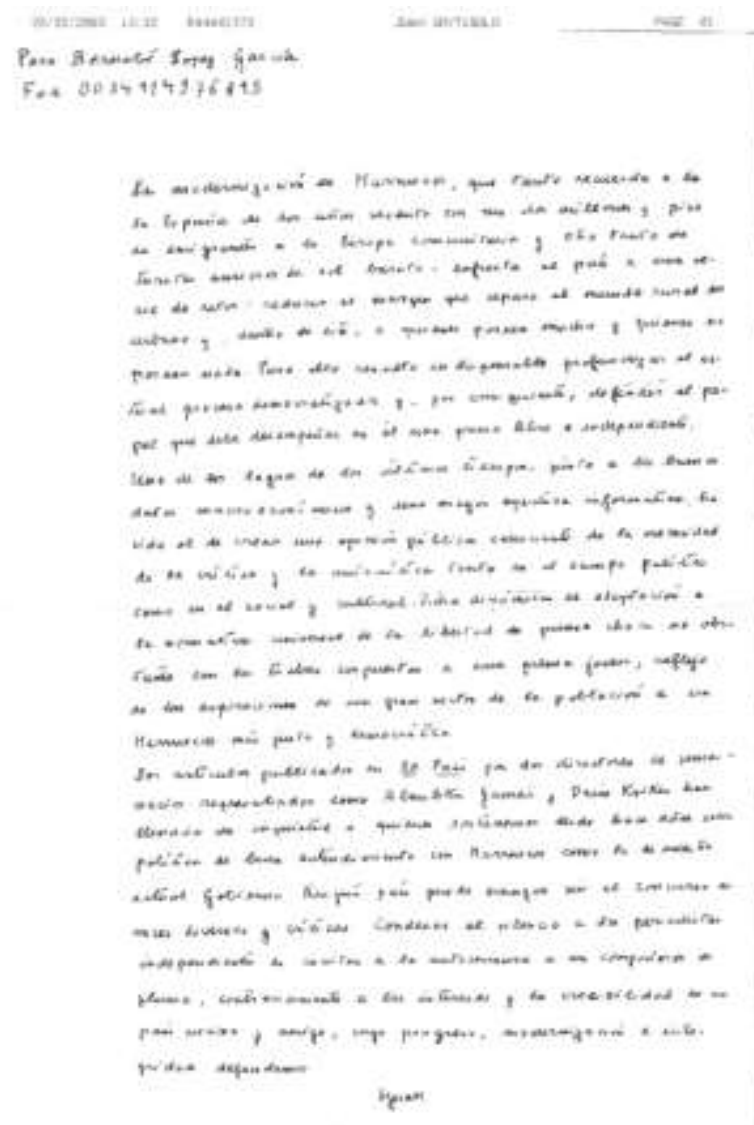

Publico el fax, pues no he podido encontrar la carta en las páginas de El País por su arcaico y caótico buscador y la ausencia de una hemeroteca que lo convierta en fuente para la historia contemporánea española como ya lo son las hemerotecas digitales de $A B C$ o La Vanguardia.

Goytisolo volvió a su apoyo a esa prensa joven e independiente marroquí, cada vez más amenazada en el Marruecos de Mohamed VI, con su artículo "La fractura lingüística del Magreb" ${ }^{36}$. No es tan explícito como en la carta transcrita, pues Goytisolo dice respecto a la carta abierta al rey Mohamed VI publicada por Ahmed Benchemsi, director de los semanarios Tel Quel y Nichan, no querer "entrar en su valoración del sistema constitucional marroquí" sino limitarse a "exponer algunas consideraciones en torno a la lengua en la que fue escrita: la darixa, llamada condescendientemente por los doctos y las 'fuerzas vivas', árabe dialectal o coloquial, por no decir 'vulgar'”. La apuesta de Goytisolo es de más largo alcance:

"Los jóvenes con quienes hablo no comparten el menosprecio oficial o erudito por su lengua materna. Esta se abre ya lentamente paso, como el tamazigh, en los medios informativos y, previsiblemente, se extenderá cada vez más. Dado que la identidad magrebí es múltiple y mutante -como lo son todas las identidades, digan lo que digan las constituciones y textos oficiales-, la darixa y el bereber común al Atlas y la Cabilia arraigarán más temprano que tarde en el campo del saber y de la cultura, por dura que sea la resistencia de los letrados y de los poderes fácticos".

Y una vez más, con motivo de la huelga de hambre llevada a cabo en demanda de una documentación que le era denegada por las autoridades de su país, por el periodista Ali Lmrabet, director que fue de los semanarios Demain Magazine y Douman, y condenado a 10 años de prohibición de ejercer su profesión en Marruecos, Goytisolo suscribió la carta a Mohamed VI que

${ }^{36}$ El País, 24 de septiembre de 2007. 
le dirigieron, entre otros, Federico Mayor Zaragoza, Margaret Atwood, John Maxwell Coetzee y otros intelectuales en julio de $2015^{37}$.

Para terminar este somero repaso sobre la relación de Juan Goytisolo con Marruecos llama la atención que entre los numerosos artículos que publicó sobre la llamada "primavera árabe", la mayoría en 2011 pero también sus secuelas en años posteriores, ninguno estuviese dedicado a Marruecos y el movimiento del 20 de febrero que sacudió las estructuras del régimen marroquí. Me consta que no fue por falta de interés o de seguimiento de lo ocurrido en Marruecos sobre todo entre los meses de enero y julio de 2011, pues tuve ocasión de comentar con él en los veranos sucesivos, en una terraza, muy querida al escritor, junto a los edificios Renschhausen de Tánger, el clima de agitación que cundió por el país y las esperanzas que suscitó. Y sin embargo, fue el martirio de Buazizi en Túnez, la plaza de la Liberación de El Cairo, la tiranía de Gadafi, Bachar El Assad o del presidente yemení los que llenaron sus artículos, alimentando así la idea de muchos de un silencio intencionado sobre la realidad que conocía y vivía a diario en la medina marrakchi.

\footnotetext{
${ }^{37}$ Ver Francisco Perejil, “Destacados intelectuales se movilizan a favor de un periodista marroquí", en El País, 22 de julio de 2015.
} 